\title{
SEGURANÇA PÚBLICA E ORGANIZAÇÕES CRIMINOSAS NO BRASIL: UMA ANÁLISE DAS FERRAMENTAS DE INVESTIGAÇÃO UTILIZADAS PELA POLÍCIA CIVIL DO ESTADO DE SÃ̃O PAULO
}

\author{
Amanda Tavares Borges 1 \\ Priscila Mara Garcia Cardoso ${ }^{2}$
}

RESUMO: A presente pesquisa, através de estudos criminológicos e de segurança pública, traça um panorama sobre as organizações criminosas no Brasil e as ferramentas de investigação disponíveis na Polícia Civil do Estado de São Paulo. Nesta toada, foi feito um apanhado dos principais conceitos sobre o tema encontrados na literatura ao longo do tempo, utilizando-se da pesquisa bibliográfica e método de revisão de literatura; depois, aborda-se a evolução legislativa sobre as Organizações Criminosas no Brasil, dando-se ênfase às inovações trazidas pela Lei $\mathrm{n}^{\circ} 12.850 / 2013$ e um (re)conhecimento de novas práticas de investigação.

Palavras-chave: Organizações criminosas; Investigação policial; Inteligência policial; Segurança pública; Polícia Civil.

\section{PUBLIC SECURITY AND CRIMINAL ORGANIZATIONS IN BRAZIL: AN ANALYSIS OF THE INVESTIGATION TOOLS AVAILABLE IN THE CIVIL POLICE OF THE STATE OF SÃO PAULO}

\begin{abstract}
This research, through criminological and public security studies, provides an overview of criminal organizations in Brazil and the investigation tools available at the Civil Police of the State of São Paulo. In this tone, an overview of the main concepts on the theme found in the literature over time has been made, using bibliographic research and literature review method; then, the legislative evolution on Criminal Organizations in Brazil is approached, emphasizing the innovations brought by Law $\mathrm{n}^{\mathrm{o}} 12.850$ / 2013 and a (re) knowledge of new investigative practices.
\end{abstract}

Keywords: Criminal organizations; Police investigation; Police intelligence; Public security; Civil police.

\section{INTRODUÇÃO}

O presente estudo traz a análise para o crime organizado, fenômeno social e político, que vem se embrenhando em praticamente todas as atividades da sociedade e evoluindo de

\footnotetext{
${ }^{1}$ Escrivã de Polícia Mestre em Direitos Difusos e Coletivos. Especialista em Direito Penal e do Trabalho. Professora da Academia de Polícia Civil de São Paulo. Docente Civil na Polícia Militar do Estado de São Paulo. Professora de ensino superior da Faculdade de Ciências Humanas de São Paulo/SP. E-mail: amanda.borges@policiacivil.sp.gov.br.

${ }^{2}$ Advogada. Mestre em Direitos Sociais. Especialista em Direito Púbico. Conciliadora. Professora de ensino superior da Faculdade de Ciências Humanas de São Paulo/SP. E-mail: Priscila.garcia@adv.oabsp.
} 
forma vertiginosa, a ponto de se tornar um desafio diário e preocupação constante para a Administração Pública nas suas diferentes esferas de atuação.

Embora tenha origem remota, o crime organizado, da maneira que hoje se apresenta, sofreu grande impacto com os processos de globalização dos mercados e flexibilização das fronteiras nacionais a partir do século XXI, o que culminou com o aumento na escala de atos ilegais praticados e de circulação de valores, na produção de redes conectadas e no emprego de aparatos tecnológicos no incremento da atividade delitiva.

Com a modernização da criminalidade, as instituições viram-se obrigadas à remodelagem de suas técnicas investigativas para a manutenção da ordem pública, bem como à adequação de todo o aparato legislativo. Considerando-se o fato de que os envolvidos com organizações criminosas agem de forma sofisticada e ousada e movimentam vultosos lucros provenientes da atividade ilícita, ao Estado resta o dever-desafio de enfrenta-los maximizando os parcos recursos que possui e respeitando o ordenamento jurídico vigente.

Nesse contexto, o presente estudo busca contribuir para a reflexão sobre o tema, traçando um panorama sobre as organizações criminosas no Brasil e as ferramentas de investigação disponíveis na Polícia Civil do Estado de São Paulo para combater esta modalidade delitiva, trazendo a análise para o campo da segurança pública, refletindo sobre estudos voltados para as reivindicações dos movimentos sociais de repressão desta forma de atuação da criminalidade, que tanto onera a todos, como o (re) conhecimento de novas práticas de atuação da criminalidade empresarial, mais articulada e globalizada, recriando a forma de apurar estas infrações e se alcançar, quando possível, este tipo de delinquente.

Assim, é feito um apanhado dos principais conceitos sobre o tema encontrados na literatura ao longo do tempo, utilizando-se da pesquisa bibliográfica e método de revisão de literatura; depois, aborda-se a evolução legislativa sobre as Organizações Criminosas no Brasil, dando-se ênfase às inovações trazidas pela Lei n ${ }^{\circ}$ 12.850/2013, que além de conceituar juridicamente a expressão "organização criminosa" e tipificar sua conduta, dispôs sobre a investigação criminal, os meios de obtenção da prova e o procedimento criminal, bem como inseriu novos tipos penais no ordenamento jurídico pátrio.

\section{NOÇÕES PROPEDÊUTICAS}


A literatura aponta que o crime em larga escala não é fenômeno recente, havendo notícias de que piratas dos séculos XVII e XVIII já possuíam uma estrutura embrionária do que hoje viria a se chamar organização criminosa. Com efeito, os piratas, àquela época, organizavam-se de maneira estável para o cometimento de crimes, contavam com redes de apoio (inclusive oficial de alguns Estados) e eram constituídos em torno de uma liderança e forte hierarquia (CUNHA, 2011, p. 02).

As Tríades Chinesas (séc. XVII), a Yakusa japonesa (séc. XVIII), a Máfia italiana e a Máfia russa (Vor v Zakone), ambas do séc. XIX, são outros exemplos de organizações consideradas criminosas, embora tenham surgido como movimentos de proteção contra a arbitrariedade dos poderosos e dos Estados em face dos hipossuficientes (LEITE SS, 2014, p. $12)$.

Impende ressaltar que o termo "máfia", em verdade, corresponde à organização criminosa existente na Sicília, sul da Itália, a Cosa Nostra (MENDRONI, 2016, p. 29), mas que se universalizou e passou a designar todas as associações criminosas com as suas principais características: "rituais e cerimônias de iniciação, juramento de eterna lealdade à organização, código de regras e valores, pacto de silêncio e uso da violência" (FONSECA, 2017. p. 42).

Na década de 1970, foi elaborado o Racketeer Inluenced and Corrupt Organizations Act, ou RICO, principal estatuto americano para o combate às organizações criminosas. Além do esforço legislativo, os agentes do Federal Bureau of Investigation (FBI) passaram a focar nas organizações criminosas, em detrimento do antigo "inimigo", o comunismo, que predominou entre as décadas de 1950 a 1960. Um dos mais famosos casos nos anos 1970 envolveu o agente infiltrado Joseph Pistone, codinome Donnie Brasco, o qual manteve-se como agente infiltrado por seis anos na máfia em Nova Iorque e cujo trabalho resultou no indiciamento de 200 criminosos e na condenação de 1002.

Os criminosos organizados vêm tirando proveito da redução das barreiras políticas e econômicas das sociedades em transição, da tecnologia de telecomunicações modernas e práticas empresariais que facilitam o comércio legítimo internacional, ou seja, o mesmo cenário que favorece o modo de reprodução capitalista fomenta o que Ferro Júnior e Dantas denominam de "globalização do crime" (ou sua "transnacionalização"), resultando na junção e engrenagem de vários tipos de crimes:

(...) A globalização ou transnacionalização do crime está associada a vários fatores, a maioria deles derivados da própria evolução tecnológica da sociedade moderna, o 
que vem dando ensejo, inclusive, ao surgimento de uma hodierna tipologia delitiva que contém os chamados "crimes cibernéticos". A prevalência desses novos crimes transcende, por isso mesmo, os limites territoriais dos Estados Nacionais, fazendo com que (...) (esses delitos) passem a ser também referidos como transnacionais, já que algumas organizações criminais modernas, ao desenvolverem hoje suas atividades, não respeitam divisas ou fronteiras nacionais, demonstrando um considerável poder de articulação e planejamento, exibidos com uma sofisticação e arrojo nunca antes observados (FERRO JÚNIOR; DANTAS, 2007).

Em 2013, na reunião do Conselho de Segurança da ONU, a avaliação atual, mais ou menos homogênea, feita por estes atores, é de que:

o crime organizado, circunscrito até os anos 1980 ao âmbito doméstico de países como os Estados Unidos, a Itália e o Japão, ganhou força e amplitude alarmante nas últimas três décadas, criando impulsos transnacionais, diversificando suas atividades, desenvolvendo-se em países avaliados como falidos e afetando diversas (PEREIRA, 2015, p. 86).

Saliente-se que o tráfico transnacional de drogas é parte importante da economia do crime organizado na América Latina, especialmente concentrado em torno da cocaína. Possui um "modo de produção" peculiar, que conta com uma divisão "do trabalho entre países produtores, países encarregados da circulação e do tráfico e países com forte mercado consumidor”. Peru, Bolívia e Colômbia ainda são considerados os maiores produtores e fornecedores de cocaína para o mundo (ADORNO, 2019, p. 34).

Nesse contexto, mister se faz elucidar alguns pontos sobre as expressões "crime organizado" e "organizações criminosas", que comumente geram debates calorosos entre os especialistas. $\mathrm{O}$ "crime organizado é fenômeno criminal sem definição legal, que caracteriza as ações praticadas por organização criminosa, confundindo-se com o conceito desta" (ANDREUCCI, 2017).

Respeitadas as particularidades de cada país e, embora não haja uma definição única para o que é uma organização criminosa, há um consenso de que o assunto envolve "crimes de grande potencial ofensivo, praticados por grupos criminosos organizados, permanentes ou duradouros, que buscam incessantemente vantagem financeira e que debilitam o Estado" (SANTOS, 2007, p. 100).

A estabilidade, tanto de hierarquia quanto de objetivos, é um predicado indispensável para a configuração das organizações criminosas e "forma o elemento que mantém unidos os integrantes do organismo, fortalecendo-o enquanto agrupamento paralelo do Estado, especializado na atividade criminosa" (EL TASSE, 2013).

As organizações criminosas podem ser classificadas em dois tipos, grupos territoriais, que agem em áreas negligenciadas pelo Estado, e os grupos traficantes, que agem motivados 
exclusivamente pelo lucro. Os grupos territoriais monopolizam a violência, "oferecendo segurança às partes que cooperam”; “cobram impostos a todas as empresas, legais e ilegais, nas áreas que controlam”. Não se submetem às leis nacionais. Quando estão profundamente arraigadas, podem oferecer muitos dos serviços que deveriam ser proporcionados pelo Estado, "como segurança, cumprimento de contratos, reformas, bem-estar, emprego, crédito e atividades culturais" (UNODC, 2010, apud BID, 2017, p.107). Os grupos territoriais usam a força bruta para controlar o espaço físico.

Os grupos traficantes, por seu turno, evitam a notoriedade e uso da violência porque a violência não é um atrativo para os negócios; concentram-se na arbitragem do contrabando internacional e são motivados exclusivamente pelo lucro (BID, 2017, p. 108). Todavia, para operacionalizar suas atividades, muitas vezes pagam "impostos" aos grupos territoriais para operar nas áreas controladas por estes. De igual modo, os grupos territoriais precisam entabular relações comerciais com os traficantes. "O relacionamento pode se tornar tão próximo que fica difícil distinguir os grupos territoriais dos grupos traficantes, mas as diferenças de foco e orientação significam que essas duas funções distintas raramente estão integradas em uma única organização" (BID, 2017, p. 108).

A infiltração de criminosos no Estado pode ocorrer por corrupção ou aliciamento do agente público para omissões dolosas ou obtenção de informações privilegiadas a respeito de estruturas físicas e capacidade de reação das instituições. Além disso, os criminosos podem ingressar de forma regular nas forças estatais, através de candidaturas a cargos públicos eletivos, concursos públicos para as Polícias, Ministério Público, Judiciário, carreiras fiscais, etc., além de receber "patrocínio" para cursos superiores, mormente Direito (CUNHA, 2011, p. 06).

Dadas as suas características atuais, o estudo do crime organizado possibilita discutir suas relações com os sistemas políticos democráticos. Há uma hipótese, corrente entre pesquisadores, de que as operações ilegais do crime organizado comprometem a persistência e sobrevivência de democracias, principalmente aquelas recém-constituídas. Há, contudo, entendimento contrário, em que algumas operações estão, de tal modo, imbricadas e enraizadas nesses sistemas que constituem parte de sua funcionalidade (ADORNO; DIAS, 2019, p. 06).

\section{LEI No 12.850/2013 E O CRIME DE ORGANIZAÇÃO CRIMINOSA}


Conforme referido, a Lei $n^{\circ}$ 12.850/2013 trouxe a definição jurídica/penal do que é organização criminosa no Brasil e, diferentemente dos textos normativos anteriores, tipificou tal conduta. Não obstante, estabeleceu as infrações penais correlatas e dispôs sobre a investigação criminal a ser deflagrada nesses casos, os meios de obtenção de prova e o procedimento criminal que deve ser adotado. $\mathrm{O}$ artigo $1^{\circ}, \S 1^{\circ}$ estipulou que:

$\S 1^{\circ}$ Considera-se organização criminosa a associação de 4 (quatro) ou mais pessoas estruturalmente ordenada e caracterizada pela divisão de tarefas, ainda que informalmente, com objetivo de obter, direta ou indiretamente, vantagem de qualquer natureza, mediante a prática de infrações penais cujas penas máximas sejam superiores a 4 (quatro) anos, ou que sejam de caráter transnacional.

Frente ao conceito acima, verifica-se que a lei em comento alterou a quantidade de pessoas necessárias para configuração da organização criminosa, passando-se da exigência de 03 (três) indivíduos para 04 (quatro). A partir dessa modificação, novo debate ascendeu na esfera jurídica no tocante a estabelecer se o conceito anterior de organização criminosa, trazido pela Lei $n^{\circ} 12.694 / 2012$, havia ou não sido revogado, haja vista que cada Lei trouxe um entendimento diverso, formando-se, assim, duas correntes doutrinárias:

\begin{abstract}
Uma primeira corrente, capitaneada por Rômulo Andrade Moreira, entende que vigoram atualmente dois conceitos de organização criminosa, um para os fins exclusivos da Lei 12.694/2012, outro, de abrangência geral, trazido pela Lei 12.850/2013 (LCO). Essa orientação se alicerça no fato de a Lei 12.850/2013 não haver observado o art. 9. ${ }^{\circ}$ da Lei Complementar 95/1998, segundo o qual "a cláusula de revogação deverá enumerar expressamente as leis ou disposições legais revogadas". Dessarte, não tendo havido revogação expressa pela LCO, esta teria preservado a vigência do art. 2..$^{\circ}$ da Lei 12.694/2012.

Diversamente (segunda corrente), com a maioria, entendemos que a nova Lei do Crime Organizado revogou tacitamente o art. 2. ${ }^{\circ}$ da Lei 12.694/2012, de maneira que há apenas um conceito legal de organização criminosa no País. É a posição de Luiz Flávio Gomes, Cezar Roberto Bitencourt, Vladimir Aras, Renato Brasileiro de Lima, Rogério Sanches Cunha e Ronaldo Batista Pinto,15 Fernando Rocha de Andrade, entre outros. Assim também entendemos, porquanto "a lei posterior revoga a anterior quando expressamente o declare, quando seja com ela incompatível ou quando regule inteiramente a matéria de que tratava a lei anterior" (art. 2. ${ }^{\circ}, \S 1 .^{\circ}$, da Lei de Introdução às Normas do Direito Brasileiro). Além disso, proclama a primeira parte do inciso IV do art. $7 .^{\circ}$ da Lei Complementar 95/1998 que, em regra, "o mesmo assunto não poderá ser disciplinado por mais de uma lei". De mais a mais, admitir-se a existência de dois conceitos de organização criminosa evidenciaria grave ameaça à segurança jurídica (MASSON; MARÇAL, 2018, p. 22) (grifos dos autores).
\end{abstract}

Além de alterar o número mínimo de componentes da organização criminosa, a Lei ${ }^{\circ}$ 12.850/13 ampliou o campo de abrangência para qualquer "infração penal”, e não somente para os "crimes". Com efeito, a Lei no 12.694/12 considera organização criminosa aquela que 
pratica crimes cuja pena máxima seja igual ou superior a quatro anos ou que sejam de caráter transnacional. Já a aludida Lei $n^{\circ} 12.850 / 13$ considera organização criminosa aquela que pratica infrações penais cujas penas máximas sejam superiores a quatro anos, ou que sejam de caráter transnacional (MARTINS, 2013).

Outra importante observação a ser feita é que a Lei nº 12.850/2013 também estendeu a aplicação do conceito de organização criminosa para outras condutas, conforme disposto no $\S 2 .^{\circ}$ do artigo $1^{\circ}$. Desse modo, as infrações penais que não sejam praticadas por intermédio de organização criminosa (na acepção técnica do termo) mas que estejam enquadradas nas duas hipóteses trazidas pelos incisos I e II serão consideradas crime de organização criminosa extensivamente, a saber:

- às infrações penais previstas em tratado ou convenção internacional quando, iniciada a execução no País, o resultado tenha ou devesse ter ocorrido no estrangeiro, ou reciprocamente;

- às organizações terroristas, entendidas como aquelas voltadas para a prática dos atos de terrorismo legalmente definidos.

O inciso I traz a hipótese da infração penal prevista em tratado ou convenção internacional cometida à distância ${ }^{3}$, como ocorre por exemplo no tráfico internacional de pessoas (CP, art. 149-A). Assim, mesmo que cometido por um só agente, este poderá responder pela aplicação extensiva da Lei nº 12.850/2013.

$\mathrm{O}$ inciso II traz a hipótese da aplicação extensiva da Lei $\mathrm{n}^{\circ}$ 12.850/2013 às organizações terroristas internacionais, reconhecidas segundo as normas de direito internacional, por foro do qual o Brasil faça parte, cujos atos de suporte ao terrorismo, bem como os atos preparatórios ou de execução de atos terroristas, ocorram ou possam ocorrer em território nacional.

Todavia, em 2013 não havia ainda conceituação sobre organizações terroristas no Brasil, tampouco tipificado a conduta de integrá-la. Essa problemática acabou sendo definitivamente superada com a edição da Lei 13.260/2016 (Lei de Terrorismo), que inaugurou o tratamento jurídico do terrorismo no ordenamento jurídico nacional e cuidou, entre outros aspectos, da definição de crimes (artigos $2 .^{\circ}, \S 1 .^{\circ} ; 3 .^{\circ} ; 5^{\circ} ;$ e $6^{\circ}$ ) e da aplicação das técnicas especiais de investigação previstas na Lei do Crime Organizado para a apuração dos atos de terrorismo (art. 16).

\footnotetext{
${ }^{3}$ Crimes à distância: também conhecidos como "crimes de espaço máximo", são aqueles cuja conduta e resultado ocorrem em países diversos. A respeito, insta lembrar que o art. 6. $^{\circ}$ do Código Penal acolheu a teoria mista ou da ubiquidade (MASSON; MARÇAL, 2018, p. 63).
} 


\section{FERRAMENTAS DE INVESTIGAÇÃO E MEIOS DE OBTENÇÃO DE PROVA}

As organizações criminosas, transitando no contexto de globalização e neoliberalismo, com a livre circulação de informações, riquezas e tecnologias, enriqueceram, maximizaram os lucros e diversificaram suas operações criminosas, criando mecanismos que tornaram cada vez mais difícil a atuação estatal.

Nesse cenário, é preciso que os órgãos encarregados da segurança pública e demais autoridades estejam sempre alerta e em busca de instrumentos que tornem sua atividade-fim mais eficaz. Ciente disso, é que o legislador pátrio, ao elaborar a Lei $\mathrm{n}^{\circ}$ 12850/2013, tomou o cuidado de estabelecer algumas ferramentas no intuito de viabilizar a colheita de prova nas investigações envolvendo as organizações criminosas.

\subsection{Colaboração premiada}

O instituto da colaboração premiada tinha previsão no ordenamento jurídico brasileiro antes de 2013 nas Leis 7.492/95 (Crimes contra o Sistema Financeiro), 8.072/90 (Crimes Hediondos), 9.034/95 (Crime Organizado), 9.613/98 (Lavagem de capitais), 9.807/99 (Proteção das vítimas e testemunhas) 11.343/06 (Lei de Drogas), 12.529/11 (CADE), mas não havia nenhum regramento específico ou detalhado que possibilitasse a efetividade prática da medida, o que veio a ocorrer apenas com a Lei 12.850/13, alterada substancialmente pela Lei 13.964, de 24 de dezembro de 2019.

\section{Colaborar significa:}

prestar auxílio, cooperar, contribuir; associando-se ao termo premiada, que representa vantagem ou recompensa, extrai-se o significado processual penal para o investigado ou acusado que dela se vale: admitindo a prática criminosa, como autor ou partícipe, revela a concorrência de outros(s), permitindo ao Estado ampliar o conhecimento acerca da infração penal, no tocante à materialidade ou à autoria (NUCCI, 2015, p. 51, grifos originais).

O acordo de colaboração premiada é "negócio jurídico processual e meio de obtenção de prova, que pressupõe utilidade e interesse públicos" (artigo 3-A). Nas palavras do Min. Ricardo Lewandowski, a colaboração é "um instrumento útil, eficaz, internacionalmente reconhecido, utilizado em países civilizados" (HC 90.688/ PR) e plasmado nas Convenções de 
Palermo (art. 26) e de Mérida (art. 37), como medida apta a auxiliar no combate ao crime organizado e à corrupção (MASSON; MARÇAL, 2018, p. 164).

Há, todavia, quem discorde desse posicionamento. Nucci (2014, p. 728-729) sintetiza os argumentos contrários à colaboração premiada encontrados na doutrina:

a) oficializa-se, por lei, a traição, forma antiética de comportamento social; b) pode ferir a proporcionalidade na aplicação da pena, pois o delator recebe pena menor que os delatados, autores de condutas tão graves quanto as dele; c) a traição, como regra, serve para agravar ou qualificar a prática de crimes, motivo pelo qual não deveria ser útil para reduzir a pena; d) não se pode trabalhar com a ideia de que os fins justificam os meios, na medida em que estes podem ser imorais ou antiéticos; e) a existente delação premiada não serviu até o momento para incentivar a criminalidade organizada a quebrar a lei do silêncio, regra a falar mais alto no universo do delito; f) o Estado não pode aquiescer em barganhar com a criminalidade; g) há um estímulo a delações falsas e um incremento a vinganças pessoais.

O recebimento da proposta para formalização de acordo de colaboração demarca o início das negociações e constitui também marco de confidencialidade. As partes deverão assinar um "Termo de Confidencialidade para prosseguimento das tratativas, o que vinculará os órgãos envolvidos na negociação e impedirá o indeferimento posterior sem justa causa" (art. 3-B, $\S 2^{\circ}$ ).

Toda tratativa sobre colaboração premiada deverá ser realizada na presença de advogado constituído ou defensor público e incumbe à defesa comprovar com documentos e outros elementos a veracidade dos fatos ilícitos narrados pelo colaborador, para os quais concorreu.

Evidentemente que o colaborador, como regra, não aceita o acordo de delação por conta de um exame de consciência e arrependimento pelos crimes que cometeu, senão porque visa a um benefício processual. De acordo com Nucci (2015, p. 52):

\footnotetext{
o valor da colaboração premiada é relativo, pois se trata de uma declaração de interessado (investigado ou acusado) na persecução penal, que pretende auferir um benefício, prejudicando terceiros. Embora assuma a prática do crime, o objetivo não é a pura autoincriminação, mas a consecução de um prêmio. Diante disso, é inevitável lastrear a condenação de alguém baseado unicamente numa delação. É fundamental que esteja acompanhado de outras provas, nos mesmos moldes em que se considera o valor da confissão.
}

Segundo o artigo $4^{\circ}$, caput, a partir do requerimento das partes, o juiz poderá conceder ao colaborador: "o perdão judicial, reduzir em até $2 / 3$ (dois terços) a pena privativa de liberdade ou substituí-la por restritiva de direitos". Todavia, estipula que a colaboração 
deve ser "efetiva e voluntária" e precisa se traduzir em um ou mais dos resultados delineados nos incisos I a V.

Outros três prêmios pela colaboração possuem previsão legal, a saber: não oferecimento de denúncia ( $\operatorname{art} .4^{\circ}, \S^{\circ}$ ), se o colaborador não for o líder da organização criminosa e for o primeiro a prestar efetiva colaboração; e redução da pena até a metade, se a colaboração for posterior à sentença ou a progressão de regime, ainda que ausentes os requisitos objetivos, se a colaboração for posterior à sentença $\left(\operatorname{art.} 4^{\circ}, \S^{\circ}\right)$.

É vedado ao magistrado participar das negociações realizadas entre as partes para a formalização do acordo de colaboração, que ocorrerá "entre o delegado de polícia, o investigado e o defensor, com a manifestação do Ministério Público, ou, conforme o caso, entre o Ministério Público e o investigado ou acusado e seu defensor" (art. $4^{\circ}, \S 6^{\circ}$ ).

No artigo $5^{\circ}$ são elencados os direitos do colaborador, como "usufruir das medidas de proteção previstas na legislação específica" (tais medidas encontram-se previstas na Lei 9.807/1999 - (Lei de Proteção a Colaboradores, Testemunhas e Vítimas); ter nome, qualificação, imagem e demais informações pessoais preservados; ser conduzido, em juízo, separadamente dos demais coautores e partícipes; participar das audiências sem contato visual com os outros acusados; não ter sua identidade revelada pelos meios de comunicação, nem ser fotografado ou filmado, sem sua prévia autorização por escrito; e cumprir pena ou prisão cautelar em estabelecimento penal diverso dos demais corréus ou condenados.

3.2 Captação ambiental de sinais eletromagnéticos, ópticos ou acústicos

O instituto da captação ambiental, também chamado de "vigilância eletrônica" (MASSON; MARÇAL, 2018, p. 253), permite que a Polícia ou eventualmente o Ministério Público instalem aparelhos aptos a gravarem som e imagem em ambientes fechados (residências, locais de trabalho, estabelecimentos prisionais etc.) ou abertos (ruas, praças, jardins públicos etc.), “com a finalidade de não apenas gravar os diálogos travados entre os investigados (sinais acústicos), mas também de filmar as condutas por eles desenvolvidas (sinais óticos)", ou ainda registrar sinais eletromagnéticos, por rádio transmissores, por exemplo, "que tecnicamente não se enquadram no conceito de comunicação telefônica, informática ou telemática" (SILVA, 2015, p. 106). 
Nucci defende a possibilidade de a captação ambiental em local público seja concretizada sem autorização do juiz, "afinal, em local público não há intimidade suficiente e qualquer pessoa, mesmo sem aparato eletrônico, pode ouvir a conversa alheia" (NUCCI, 2014. p. 725).

\subsection{Ação controlada}

A ação controlada é um meio de investigação existente em leis de diversos países e encontra previsão na Convenção de Palermo (arts. $2^{\circ}$ e 20), na Convenção de Viena sobre o tráfico ilícito de entorpecentes e, de forma análoga, na Convenção das Nações Unidas contra a corrupção e na Convenção Interamericana contra o Tráfico de Armas. Também é conhecida por "entrega vigiada".

No Brasil, antes da Lei n. 12.850/13, a ação controlada era prevista no art. $2^{\circ}$, II, na Lei 9.034/95, no art. 33, II da Lei n. 10.409/02 e no art. 53, II da Lei de Drogas n. $11.343 / 2006$.

Para Greco Filho (2014, p. 54), “a ação controlada não é uma prova nem um meio de prova. É um instrumento, uma estratégia, uma prática ou uma técnica para a obtenção de provas ou informações. A prova ou o meio de prova será o que for possível obter com o retardamento da ação policial”.

A ação controlada ocorre quando o agente público aguarda o momento oportuno para atuar, a fim de obter, com esse retardamento, um resultado mais eficaz em sua diligência. Ele posterga, com essa estratégia, a prisão em flagrante do infrator, para "obter uma prova mais robusta e mesmo uma diligência mais bem-sucedida. Daí porque se costuma denominar essa espécie de flagrante como retardado, esperado, diferido ou prorrogado" (CUNHA; PINTO, 2014, p. 90).

3.4 Acesso a registros de ligações telefônicas e telemáticas e outros dados cadastrais

A Seção IV da Lei $n^{\circ}$ 12.850/2013 disciplinou taxativamente que o Delegado de Polícia e o Ministério Público terão acesso a registros, dados cadastrais do investigado, documentos e informações, independentemente de autorização judicial (art. 15). A expressão “dados cadastrais do investigado" compreende apenas a "qualificação pessoal, a filiação e o 
endereço mantidos pela Justiça Eleitoral, empresas telefônicas, instituições financeiras, provedores de internet e administradoras de cartão de crédito", conforme citado dispositivo legal.

Além dessas informações, é possível o acesso direto (sem autorização judicial) e permanente do juiz, do Ministério Público ou do Delegado de Polícia, junto às empresas de transporte, "aos bancos de dados de reservas e registro de viagens" (artigo 16).

O artigo 17 estabelece, ainda, que as concessionárias de telefonia fixa ou móvel deverão manter à disposição das autoridades mencionadas no art. 15 "registros de identificação dos números dos terminais de origem e de destino das ligações telefônicas internacionais, interurbanas e locais", pelo prazo de cinco anos.

A obtenção de dados cadastrais, mantidos pela Justiça Eleitoral (normalmente endereço mais atualizado), por empresas telefônicas, instituições financeiras, provedoras de Internet e cartões de crédito não se inclui nas informações que são protegidas pelo sigilo em decorrência da observância dos direitos e garantias individuais das pessoas físicas. Por essa razão, os órgãos encarregados da persecução penal podem acessá-las de forma mais célere e eficiente, e assim levar adiante uma normalmente complexa investigação que envolva Organizações Criminosas.

\subsection{Interceptação de comunicações telefônicas e telemáticas}

A interceptação pode ser definida como o "ato de imiscuir-se em conversa alheia, seja por meio telefônico ou computadorizado, seja por formas abertas ou ambientais, abrangendo também as comunicações realizadas pela internet” (NUCCI, 2013, p. 42). É um meio excepcional de obtenção de prova que poderá ser utilizado tanto na persecução penal, quanto na fase judicial e, em ambos os casos, depende de prévia autorização judicial fundamentada com os pressupostos do fumus boni iuris e periculum in mora e com a indicação dos meios a serem empregados.

A interceptação pressupõe que os interlocutores desconhecem a ingerência do terceiro na conversa. Existem, todavia, modalidades de interceptação que contam com a colaboração de um dos interlocutores, conforme leciona Nucci (2013, p. 43-44): a escuta telefônica é a interceptação em que um dos interlocutores tem a ciência de sua realização; a escuta ambiental é a captação e gravação realizada por terceiro, em lugar público e com o 
conhecimento de um dos interlocutores; a gravação clandestina é aquela em que um dos interlocutores grava a conversa telefônica sem a ciência do outro; e a gravação ambiental é aquela em que um dos interlocutores grava a conversa realizada em local público, sem ser por telefone, sem o conhecimento do interlocutor.

A interceptação telefônica encontra guarida na Constituição Federal, em seu artigo $5^{\circ}$, inciso XII, mas o tema é disciplinado pela Lei $n^{\circ}$ 9.296/96, que foge ao escopo desta pesquisa, porém cumpre referir que tal lei regulamentou a forma e as hipóteses de não aplicabilidade da interceptação em três situações: caso não haja indícios de autoria ou participação na infração; se a prova puder ser obtida de outra maneira; e se o fato a ser investigado constitua infração penal punida com pena máxima de detenção (BITENCOURT; BUSATO, 2014, p. 102).

\subsection{Afastamento dos sigilos financeiro, bancário e fiscal}

Apesar de a Constituição Federal erigir à categoria de direito fundamental a inviolabilidade da intimidade e da vida privada, nos estritos lindes do que se encontra preceituado no art. 5. ${ }^{\circ}, \mathrm{X}$, é cediço que os direitos individuais não podem constituir salvaguarda para práticas ilícitas, conforme pacificado pela Supremo Tribunal Federal ${ }^{4}$. Desse modo, vem se tornando rotineiras as representações pela decretação do afastamento do sigilo financeiro, bancário, fiscal e até bursátil nos casos de investigação às organizações criminosas.

A Lei Complementar $n^{\circ} 105 / 01$ tratou de disciplinar como poderá ser feito o afastamento do sigilo, tendo a Lei $\mathrm{n}^{\circ} 12.850 / 13$ apenas mencionado em seu artigo $3^{\circ}$, inciso VI, que poderá ser utilizado este meio excepcional de prova para a persecução penal, utilizando-se desta forma os conceitos e procedimentos trazidos pela legislação específica.

$\mathrm{O} \S 4^{\circ}$ do artigo $1^{\circ}$ da Lei Complementar $n^{\circ} 105 / 01$ dispõe que poderá ser decretado a quebra de sigilo para a apuração de qualquer ilícito, tanto na fase inquisitorial como na

\footnotetext{
4 "Em face da concepção constitucional moderna de que inexistem garantias individuais de ordem absoluta, mormente com escopo de salvaguardar práticas ilícitas (v.g. $\mathrm{HC} \mathrm{n}^{\circ} 70.814 / \mathrm{SP}$ ), a exceção constitucional ao sigilo alcança as comunicações de dados telemáticos, não havendo que se cogitar de incompatibilidade do parágrafo único do art. $1^{\circ}$ da Lei 9.296/96 com o art. $5^{\circ}$, inciso XII, da Constituição Federal”. (RHC 132.115, rel. min. Dias Toffoli, j. 6-2-2018, 2a T, DJE de 19-10-2018).
} 
judicial, além de frisar em seu inciso IX, especialmente os crimes praticados por organizações criminosas.

3.7 Infiltração, por policiais, em atividade de investigação.

A infiltração é uma técnica especial, excepcional e subsidiária de investigação criminal, que depende de prévia autorização judicial, possuindo como características a dissimulação e o sigilo. O objetivo do agente de polícia judiciária inserido no bojo de uma organização criminosa é "desarticular sua estrutura, prevenindo a prática de novas infrações penais e viabilizando a identificação de fontes de provas suficientes para justificar o início do processo penal" (SANNINI NETO, 2016).

Nas palavras de Mendroni:

Consiste basicamente em permitir a um agente da polícia ou de serviço de
inteligência infiltrar-se no seio da organização criminosa, passando a integrá- la como
se criminoso fosse-, na verdade como se um novo integrante fosse. Agindo assim,
penetrando no organismo e participando das atividades diárias, das conversas,
problemas e decisões, como também por vezes de situações concretas, ele passa a ter
condições de melhor compreendê-la para combatê-la através do repasse das
informações as autoridades (MENDRONI, 2016, p.118-119).

A Lei $n^{\circ} 12.850 / 2013$ tratou de prever tal instituto como meio especial de obtenção de prova nas investigações contra as organizações criminosas, em consonância ao disposto na Convenção de Palermo (art. 20, item 1). De modo semelhante, sem entrar em maiores detalhes procedimentais, a Lei 11.343/2006, no art. 53, I, preconizou ser possível, em qualquer fase da persecução criminal relativa aos crimes previstos na Lei de Drogas, "a infiltração por agentes de polícia, em tarefas de investigação, constituída pelos órgãos especializados pertinentes", mediante autorização judicial e a oitiva do Ministério Público.

O mencionado artigo 10 assim dispõe sobre a infiltração de agentes de polícia:

Art. 10. A infiltração de agentes de polícia em tarefas de investigação, representada pelo delegado de polícia ou requerida pelo Ministério Público, após manifestação técnica do delegado de polícia quando solicitada no curso de inquérito policial, será precedida de circunstanciada, motivada e sigilosa autorização judicial, que estabelecerá seus limites (grifos nossos).

Conforme se depreende da leitura do dispositivo supra, o legislador deixa claro que a infiltração de agentes deve ser utilizada em "tarefas de investigação" e somente por "agentes de polícia" com esta atribuição, fazendo menção sobre a necessidade de representação do Delegado de Polícia ou a sua manifestação (parecer) no caso de a medida ser solicitada pelo 
Ministério Público. "Isto, pois, o delegado de polícia é o chefe da polícia judiciária, sendo a autoridade com aptidão para verificar as condições técnicas e estruturais para a realização deste meio investigativo" (SANNINI NETO, 2016).

\begin{abstract}
Como "agentes de polícia" devem ser entendidos os membros das corporações elencadas do art.144 da Constituição Federal, a saber: Polícia Federal propriamente dita, rodoviária e ferroviária; e Polícia Estadual (civil, militar e corpo de bombeiros), observadas, nesta última hipótese, a organização própria de cada unidade da federação. Mas nem todos estes órgãos possuem atribuições investigativas. Com efeito, o inc. I deste dispositivo constitucional atribui à polícia federal a tarefa de "apurar infrações penais". Já o inc. IV, $\S 4^{\circ}$ do art.144 da CF, comina às polícias civis estaduais essa tarefa investigativa. São, portanto, os policiais federais e civis aqueles habilitados a servirem como agentes infiltrados (CUNHA; PINTO, 2014, p. 98).
\end{abstract}

Excepcionalmente, todavia, com as novas competências da Justiça Militar instituídas pela Lei 13.491/2017, que ampliou sobremaneira o conceito de crime militar, em tempo de paz, e passou-se a considerar como tal não apenas os delitos inscritos no Código Penal Militar (CPM) mas, também, os previstos na legislação penal, inclusive os catalogados na Lei ${ }^{\circ}$ 12.850/2013, se acaso cometidos por militares da ativa em uma das condições do inciso II do art.9. ${ }^{\circ}$ do CPM, Masson e Marçal (2018, p. 311) vêm a possibilidade de ser judicialmente autorizada a infiltração por um militar para apurar casos em que seus pares constituam organização criminosa.

A doutrina divide a infiltração didaticamente em duas modalidades:

\begin{abstract}
3.2.1.1 Light Cover ou infiltração leve, com duração máxima de seis meses e que exige menos engajamento por parte do agente infiltrado; e b) Deep Cover ou infiltração profunda, que se desenvolve por mais de seis meses, exigindo total imersão no bojo da organização criminosa, sendo que na maioria dos casos o agente infiltrado assume outra identidade e praticamente não mantém contato com a sua família (SANNINI NETO, 2016).
\end{abstract}

Nos termos do artigo $10, \S 3^{\circ}$, da Lei de Organizações Criminosas ambas as modalidades são admitidas no Brasil, admite-se as duas formas de infiltração, uma vez que este procedimento pode ser adotado por seis meses (Light Cover), mas com a possibilidade de renovações, superando este interregno (Deep Cover). O parágrafo único do artigo $13^{5}$ prevê hipótese de excludente de culpabilidade caso o agente infiltrado precise cometer algum crime, a fim de preservar sua identidade e obter provas para desmantelar a organização criminosa, sempre tendo em vista que não dispõe de carta branca para delinquir. A causa de exclusão de

\footnotetext{
${ }^{5}$ Parágrafo único do art. 13, da Lei 12850/2013: "não é punível, no âmbito da infiltração, a prática de crime pelo agente infiltrado no curso da investigação, quando inexigível conduta diversa".
} 
culpabilidade somente incidirá se ele guardar a devida proporcionalidade entre a sua conduta e a finalidade da investigação respondendo pelos excessos cometidos (MASSON; MARÇAL, 2018, p. 326).

A Lei 12850/2013 não se olvidou de assegurar alguns direitos ao agente infiltrado, os quais estão elencados no artigo 14.

Por fim, cumpre registrar a possibilidade de a infiltração se dar por meio virtual. Com efeito, a Lei 13.441/17 instituiu no Estatuto da Criança e do Adolescente a "infiltração policial virtual", caracterizada por ser efetuada na internet (artigos 190-A a 190-E da Lei 8.069/90). Admite-se a infiltração policial virtual basicamente em 3 categorias de delitos: a) pedofilia (artigos 240, 241, 241-A, 241-B, 241-C e 241-D do ECA); b) crimes contra a dignidade sexual de vulneráveis: estupro de vulnerável (artigo 217-A do CP), corrupção de menores (artigo 218 do CP), satisfação de lascívia (artigo 218-A do CP) e favorecimento da prostituição de criança ou adolescente ou de vulnerável (artigo 218-B do CP); c) invasão de dispositivo informático (artigo 154-A do CP).

\subsection{Cooperação entre instituições e órgãos governamentais}

A cooperação entre instituições e órgãos governamentais busca propiciar um cenário de ajuda mútua e concentração de esforços para desbaratar o crime organizado, e ultrapassa o caráter nacional, podendo haver conexões com entes federativos internacionais. A Convenção de Palermo, em seu artigo 28, também fez menção ao assunto.

Masson e Marçal salientam a importância da "organização do Estado contra o crime organizado", sendo fundamental a interação entre os diversos ramos do Ministério Público, as polícias (polícia federal, polícia rodoviária federal, polícia ferroviária federal, polícias civis, polícias militares e corpos de bombeiros militares - CF, art. 144, I a V), autarquias, controladorias, corregedorias, instituições financeiras, Receita Federal, Tribunais de Contas e todos os demais órgãos e instituições que têm acesso a dados relevantes para a persecução criminal, unindo-se em torno "desse objetivo comum de simbiose de informações e compartilhamento de provas" (MASSON; MARÇAL, 2018, p. 332).

No entender de Silva (2015, p. 123), a cooperação entre instituições eórgãos federais, distritais, estaduais e municipais não deve ser tecnicamente considerada um meio probatório, 
mas "uma estratégia que pode possibilitar a obtenção de provas constantes nos arquivos dos entes estatais referidos".

\section{CONCLUSÃO}

O crime organizado se insere em uma profunda, complexa e dinâmica matriz. No Brasil, o debate público sobre o tema tem girado em torno, principalmente, das modalidades associadas ao comércio de drogas ilícitas, ao contrabando de mercadorias diversas, especialmente, armas de fogo, à extorsão que, em geral, está associada à monopolização da oferta de determinados serviços e mercadorias em alguns territórios e à lavagem de capitais.

Conclui-se que para a Polícia Civil enfrentar a criminalidade organizada é necessário: (i) capacitar seus agentes, sobretudo para que estejam aptos a desenvolver atividade de inteligência policial para subsidiar as investigações; (ii) propiciar cursos de reciclagem teórica e prática em armamento e tiro (não se pode esperar que o policial enfrente criminosos com fuzis estando armado com um "revólver enferrujado", nem se almeja bandos armados sem doutrina e estratégia); (iii) aperfeiçoar as estruturas físicas e materiais, tanto em relação ao armamento, viaturas e equipamentos de segurança, quanto equipamentos informáticos e dispositivos tecnológicos (é inaceitável, por exemplo, que os policiais tenham que usar seus próprios smartphones para obter alguma informação disponível somente nesse tipo de aparelho); (iv) integrar as instituições policiais e o judiciário, pois o corporativismo e as rivalidades em nada auxiliam o combate às organizações criminosas; e (v) pressionar as autoridades governamentais em busca incessante por uma legislação eficaz.

Foi revelado na Lei 12.850/13 um facho de luz e esperança por dias melhores, contudo, urge superar a corrupção sistêmica que acomete o Estado, incluindo os órgãos responsáveis pela segurança pública. Os meios de obtenção de prova trazidos pela referida lei, os sistemas de informática disponíveis na intranet, os recursos propiciados pela internet, aliados às tradicionais técnicas policiais (campana, recognição visuográfica de local de crime, pesquisa de campo, etc.,) podem ensejar uma eficiente persecução penal por parte da Polícia Civil de São Paulo e uma vigorosa e concreta resposta do Estado à proliferação dos fenômenos delitivos praticados por organizações criminosas. 


\section{REFERÊNCIAS}

ADORNO, Sérgio. Fluxo de operações do crime organizado: questões conceituais e metodológicas. In: ADORNO, Sérgio. DIAS, Camila N. (Orgs.). Dossiê Crime Organizado. RSB: Revista Brasileira de Sociologia / Sociedade Brasileira de Sociologia - SBS. - Vol. 07, $\mathrm{N}^{\circ}$ 17. Set.-Dez 2019, p. 33-54. Disponível em: http://www.sbsociologia.com.br. Acesso em: 13 fev. 2020.

ANDREUCCI, Ricardo Antônio. Crime Organizado, Organização Criminosa e Associação Criminosa. Empório do Direito [online]. 19 jan. 2017. Disponível em: https://emporiododireito.com.br/leitura/crime-organizado-organizacao-criminosa-eassociacao-criminosa-por-ricardo-antonio-andreucci. Acesso em: 04 jan. 2020.

BID - Banco Interamericano de Desenvolvimento. Os custos do crime e da violência: novas evidências e constatações na América Latina e Caribe. Washington: Ed.: Laura Jaitman, 2017.

BITENCOURT, Cezar Roberto; BUSATO, Paulo Cesar. Comentários à lei de organização criminosa: Lei ${ }^{\circ}$ 12.850/2013. São Paulo: Saraiva, 2014.

CUNHA, Danilo Fontenele Sampaio. Criminalidade Organizada: antigos padrões, novos agentes e tecnologias. Ponto Urbe [Online]. Revista do Núcleo de Antropologia Urbana da USP, 8, 2011. Disponível em: http://journals.openedition.org/pontourbe/1752. Acesso em: 14 fev. 2020.

CUNHA, Rogério Sanches; PINTO, Ronaldo Batista. Crime Organizado - Comentários à nova lei sobre o Crime Organizado - Lei nº12.850/2013. 2a ed. Salvador: Juspodivm, 2014.

EL TASSE, Adel. Nova Lei do Crime Organizado. Artigo [online]. JusBrasil, 2013. Disponível em: http://adeleltasse.jusbrasil.com.br/artigos/121933118/nova-lei-decrimeorganizado. Acesso em: 04 fev. 2020.

FERRO JÚNIOR, Celso Moreira; DANTAS, George Felipe de Lima. A descoberta e a análise de vínculos na complexidade da investigação criminal moderna. Revista Jus Navigandi [online]. ISSN 1518-4862, Teresina, ano 12, n. 1441, 12 jun. 2007. Disponível em: https://jus.com.br/artigos/10002. Acesso em: 11 jan. 2020.

FONSECA, Cibele Benevides Guedes. Colaboração premiada. Belo Horizonte: Del Rey, 2017.

LEITE, Sara Souza. O Emprego das fontes abertas no âmbito da atividade de inteligência policial. Brasília: Revista Brasileira de Ciências Policiais, v. 5, n. 1, p. 11-45, jan/jun 2014. Disponível em: http://www.sindipoldf.org.br/arquivos/93bea178e0.pdf. Acesso em: 16 jan. 2020.

MARTINS, José Eduardo F. de A. O conflito conceitual de organização criminosa nas Leis $\mathbf{n}^{\mathbf{0}}$ 12.694/12 e 12.850/13. Revista Jus Navigandi, ISSN 1518-4862, Teresina, ano 18, n. 3814,

Revista de Movimentos Sociais e Conflitos | e-ISSN: 2525-9830 | Encontro Virtual | v. 6 | n. 2 |

p. 42 - 60 | Jul/Dez. 2020. 
10 dez. 2013. Disponível em:

https://jus.com.br/artigos/26108. Acesso em: 16 jan. 2020.

MASSON, Cleber. MARÇAL, Vinicius. Crime Organizado. $4^{\text {a }}$ Ed., rev., atual. e ampl. Rio de Janeiro: Forense; São Paulo: MÉTODO, 2018.

NUCCI, Guilherme de Souza. Organização criminosa. 2. ed. rev., atual. e ampl. Rio de Janeiro: Forense, 2015.

NUCCI, Guilherme. Leis penais e processuais penais comentadas. 8. ed. V. 2. Rio de Janeiro: Forense, 2014.

NUCCI, Guilherme de Souza. Organização Criminosa: Comentários à Lei 12.850, de 02 de agosto de 2013. São Paulo: Revisa dos Tribunais, 2013.

PEREIRA, Paulo. Os Estados Unidos e a ameaça do crime organizado transnacional nos anos 1990. Revista Brasileira de Política Internacional, v. 58, n. 1, p. 84-107, 2015.

SANNINI NETO, Francisco. Infiltração de agentes é atividade de polícia judiciária. ConJur. 05 ago. 2016. Disponível em: https://www.conjur.com.br/2016-ago- 05/sanniniinfiltracao-agentes-atividade-policia-judiciaria\#_ftn3. Acesso em: 04 fev. 2020

SANTOS, Getúlio Bezerra. A hora e a vez de derrotar o Crime Organizado. Estudos Avançados, v.21 n.61. Universidade de São Paulo: São Paulo set./dez. 2007, p.99- 105. Disponível em: http://dx.doi.org/10.1590/S0103-40142007000300001. Acesso em 05.02.2020.

SILVA, Eduardo Araújo da. Organizações criminosas: Aspectos Penais e Processuais da Lei nº 12.850/13. 2. ed. São Paulo: Atlas, 2015. 